\title{
Effects of Geometrical parameters on Numerical Modeling of Pavement Granular Material
}

\author{
Behzad Ghadimi ${ }^{1}$, Hossein Asadi ${ }^{1}$, Hamid Nikraz ${ }^{1}$, Colin Leek ${ }^{1}$ \\ ${ }^{1}$ Curtin University, WA, Australia, Phone: +61 89266 7573, Fax: +61 89266 \\ 2681, email: behzad.ghadimi@postgrad.curtin.edu.au
}

\begin{abstract}
Numerical modeling of the granular pavement materials is one of the modeling approaches which can be used to predict material response to specific loading conditions. This modeling is dependent on many factors and variables and includes assumptions for material behavior, loading conditions, geomechanical properties and geometrical parameters. In this study in-depth research has been undertaken to determine the sensitivity of geometrical parameters on pavement numerical modeling.

Geometrical parameters are all those parameters that can be used to define a numerical model including layer thickness, meshing system and nature of the model (2D or 3D). In this study a layered granular pavement has been modeled through ABAQUS which is a general finite element program. The results have been compared with layered elastic theory by CIRCLY and KENLAYER.

This study will deal with three kinds of modeling being 2D axisymmetric, 2D plain strain and a complete 3D model. In each of these three models, the influence of layer thickness, elements type and mesh density has been investigated. The results have been presented, compared and discussed in order to identify the most influential parameters.
\end{abstract}

\section{INTRODUCTION}

In the pavement engineering field, there is a growing trend to use mechanistic design procedure. These methods rely on the calculation of the strain and stress in the layers of pavement. To do this, the most common approach is the numerical approach through which the layered pavement system is modeled and solved by one of the familiar continuum mechanic assumptions (linear elastic, nonlinear elastic, elastoplastic, etc.).

There are two main categories in the numerical modeling; that using an analytical solution provided from theory of elasticity or implementation of finite element technique to solve the general equilibrium of the layered system.

While the first approach has traditionally been used as the basis for the mechanistic design, finite element modeling will be increasingly used by pavement designer. The apparent advantage of the finite element models is its capabilities to model various types of mechanical behavior, loading conditions and geometrical parameters. However, compared to layered elastic solutions finite element methods are more complicated and time consuming. 
Finite element modeling provides a more comprehensive understanding of the pavement response to stress distribution, strain and displacement. Therefore, comparing these two methodologies and the sensitivity to geometrical parameters is of considerable value.

\section{NUMERICAL MODELING OF THE LAYERED PAVEMENT MATERIALS}

Using linear elastic theory, an analytical response for the layered semiinfinite half-space can be calculated. The assumptions are that stress-strain behavior is linear elastic and the pavement domain has no limit in horizontal direction. In vertical direction there is a horizontal stress-free surface at top of the medium while the supporting layer (subgrade) is extended to infinite depth.

D.S Gedafa (2006) used KENLAYER and HDM-4 to analyze flexible pavement performance. Hadi and Symons (1996) have compared results of CIRCLY program with finite element model constructed in MSC/NASTRAN and STRAND. Tutumluer (2003) compared the results of pavement modeling through finite element program GT-PAVE and CIRCLY for a cross anisotropic model.

By applying partial differential equations of the equilibrium condition, finite-element method (FEM) is a numerical approach that will approximate the solution of an engineering structure under different boundary conditions.

While there are specific advantages, special consideration is required in the field of the numerical modeling of the layered pavement system. There are many aspects that need to be verified before the output results can be considered reliable. One of these aspects is geometrical structure of the model. It has been recognized that effect of geometrical structure on the model output cannot be ignored.(Cho 1996).

Cho et. Al (1996) investigated the effect of various parameters including; element size, aspect ratio, and type of FEM formulation. These formulations (which are used as the basis of comparison in the current study) are 2-D plain strain, 2-D axisymmetric and a full three dimensional formulation. The FEM was constructed in the commercial software package, ABAQUS while the layered elastic model was constructed in the BISAR. It was concluded that the 3-D and axisymmetric FEM models provide closest agreement for the analysis of traffic loading.

Zaghloul and White (1993) have used ABAQUS to model the three dimensional behavior of a pavement layered system under dynamic loading. Mallela and George (1994), Uddin and Pan (1994) Mallela and George (1994) and Uddin and Pan (1994) used the finite element computer package ABAQUS with a three dimensional model in their studies.

Myers et. al (Myers, Roque et al. 2001) studied FEM models in both axisymmetric and two dimensional analysis. They acknowledged that 3-D model is more accurate but it is also more complicated and takes more computer time. They concluded that a 2-D analysis can be an acceptable approximation for 3-D analysis, however, the discrepancies are dependent of the characteristics of the pavements structure. 
Kim and Tutumluer ((2006), (2007) and (2009)) used the general purpose finite element computer program ABAQUS in their study on modeling the nonlinear behavior of stress-dependent pavement foundation (subgrade). They used both 2-D axisymmetric and three dimensional modeling in their study.

Holanda (Holanda, Parente Junior et al. 2006) implemented a new technique using Objective-Oriented Programing. They used this technique to model both axisymmetric and three dimensional models. The results are evaluated against existing computational and analytical solutions.

Bodhinayake (2008) has used ABAQUS to model a full three dimensional analysis. Nonlinearity in subgrade soil has been studied while other pavement layer has been modeled as a linear elastic material.

\section{REVIEW OF THE SOFTWARES}

Two well-accepted pavement design programs, KENLAYER and CIRCLY, calculate pavement system responses (stress, strain, deformation, etc.) based on this elastic theory.

KENLAYER is a generally accepted computer program (Huang (1993) and (2004)) program which can model pavement layers as linear elastic, nonlinear elastic or Mohr-Coulomb elastoplastic materials. The main core of KENLAYER is the solution for an elastic multilayer system under a circular loaded area.

CIRCLY (Wardle (1977)) is a computer program for pavement material analysis. It can model materials either isotropic or anisotropic. The load is considered as the tyre pressure uniformly distributed over a circular area. The analysis is assumed to be under static condition and superposition principle is valid.

Released in 1978, ABAQUS is an engineering simulation programs, based on the finite element method that can solve problems ranging from linear analyses to the nonlinear simulations. It is available to model a range of geometrical forms. ABAQUS can model the mechanical behavior of geotechnical materials such as soils and rock. (ABAQUS (Hibbit 2010))

\section{CURRENT STUDY}

In this study the effect of geometrical parameters on the pavement mechanical response has been investigated. Three programs (ABAQUS, KENLAYER and CIRCLY) has been manipulated to simulate pavement layers. The FEM model has been constructed in three dimensional, axisymmetric two dimensional and plain strains formulation. Mesh density and effect of element type on the analysis has been studied. The effect of variation of asphalt layer thickness and base layer thickness has also been analysed. The result are presented and concluded.

\section{NUMERICAL MODELING}

Duncan et al. (1968) first used the finite element approach in flexible pavements analysis. Huang (1969) calculated stresses and displacements in nonlinear soil using finite element modeling. Since then there have been many 
authors who have employed numerical modeling to calculate induced damage in pavement layers including the asphalt layer, base and subgrade.

Modeling of flexible pavement is undertaken by assuming specific material behavior and simplification of the actual geometry. In this paper the effect of the geometrical assumption is considered.

\section{GEOMETRICAL FORMULATION}

In this study three geometrical formulations has been modeled; three dimensional geometry, 2-D plane strain and 2-D axisymmetric formulation.

In three-dimensional elastic analysis the stress and strain are related as shown in Equation 1.(Hai-Sui Yu (2006)):

$$
\begin{gathered}
\varepsilon_{x x}=\frac{1}{E}\left[\sigma_{x x}-v\left(\sigma_{y y}+\sigma_{z z}\right)\right] \\
\varepsilon_{y y}=\frac{1}{E}\left[\sigma_{y y}-v\left(\sigma_{x x}+\sigma_{z z}\right)\right] \\
\varepsilon_{z z}=\frac{1}{E}\left[\sigma_{z z}-v\left(\sigma_{x x}+\sigma_{y y}\right)\right]
\end{gathered}
$$

Where:

$\sigma$ is the normal stress along the axes.

$\varepsilon$ is the normal strain along the axes.

$\mathrm{E}$ is the elastic modulus of the materials.

$v$ is the Poisson ratio.

Three dimensional modeling is considered to be the most accurate representation of the true condition. In the pavement modeling, however, there is a restriction of boundary condition in three dimensional modeling. In reality the pavement is effectively infinite in at least two dimensions and large in the third being the width of the pavement, but in the 3-D model, only part of the whole continuous medium can be selected for simulation purpose. This selected part is then constrained with boundary conditions (such as a fixed or roller boundary condition). The three dimensional model also needs a considerably larger time for computation.

One of the common simplifications in the field of geomechanical modeling is the plane strain assumption. According to the plane strain assumption one of the strain component (say $\varepsilon_{z z}$ ) is zero and this assumption can significantly reduce the computation effort. The plane strain represents a case in which one of the modeling dimensions is extremely longer than the other two. This condition is clearly applicable to pavement modeling.

However, the main limitation of this 2-D modeling is that pressure load of tyres will be extended to infinity which leads to severe loading conditions. Therefore while the actual loading area should be an elliptical shape, the modeled loading in plane strain is a line load (Cho, McCullough et al. 1996). Equation 2 illustrates the stress-strain relationship in assumed plane strain 
condition (Hai-Sui Yu (2006)):

$$
\begin{aligned}
\sigma_{x x} & =\frac{(1-v) E}{(1+v)\left(1-v^{2}\right)}\left(\varepsilon_{x x}+\frac{v}{1-v} \varepsilon_{y y}\right) \\
\sigma_{y y} & =\frac{(1-v) E}{(1+v)\left(1-v^{2}\right)}\left(\varepsilon_{y y}+\frac{v}{1-v} \varepsilon_{x x}\right) \\
\sigma_{z z} & =\frac{E}{(1+v)} \varepsilon_{x y}
\end{aligned}
$$

Axisymmetric formulation is a useful simplification of 3-D condition. In this case the strain-stress relation is restated in the cylindrical coordination. Axisymmetric is a very interesting approach to model a two dimensional model which represents a section of the three dimensional model as given in Equation 3.

$$
\begin{aligned}
& \varepsilon_{\mathrm{r}}=\frac{1}{\mathrm{E}}\left(\sigma_{\mathrm{r}}-v \sigma_{\mathrm{z}}\right) \\
& \varepsilon_{\mathrm{z}}=\frac{1}{\mathrm{E}}\left(\sigma_{\mathrm{z}}-v \sigma_{\mathrm{r}}\right)
\end{aligned}
$$

Where

$\sigma_{\mathrm{r}}$ is the radial stress.

$\sigma_{\mathrm{z}}$ is the vertical stress.

$\varepsilon_{\mathrm{r}}$ is the radial strain.

$\varepsilon_{\mathrm{z}}$ is the vertical strain.

$\mathrm{E}$ is the elastic modulus of the materials.

$v$ is the Poisson ratio.

The computational intensiveness is similar to the 2-D plane strain formulations. The main limitation is that the load can only be modeled as a circular area, and dual tyres or multiple axles is impossible in this formulation. The interface shear is also neglected and cracks and shoulder conditions are not considered (Cho, McCullough et al. 1996).

\section{CHARACTERISTICS OF THE MODEL}

The sample section of layered pavement with same materials properties and loading characteristics is modeled in CIRCLY, KENLAYER and ABAQUS. Figure 1 illustrates geometrical dimension of the modeled pavement.

The material properties are listed in Table 1. All layers are assumed to behave linear elastically under a $0.75 \mathrm{MPa}$ pressure loading, which is applied over a circular area of $90-\mathrm{mm}$ radius. This is the normal representation of the tyre pressure in AUSTROADS (AUSTROADS (2004)).

Figure 1 illustrate the geometry of the first constructed model in KENLAYER and CIRCLY. To investigate the effects of geometrical parameters 
on the analysis, the materials properties are assumed to be consistent along the whole analyses.

Table 1. Material Properties for KENLAYER and CIRCLY programs

\begin{tabular}{cccc}
\hline Layer & $\begin{array}{c}\text { Thickness } \\
(\mathrm{mm})\end{array}$ & $\begin{array}{c}\text { Elastic } \\
\text { Modulus } \\
(\mathrm{MPa})\end{array}$ & $\begin{array}{c}\text { Poisson } \\
\text { Ratio }\end{array}$ \\
\hline $\begin{array}{c}\text { Asphalt (AC) } \\
\text { Granular } \\
\text { (Base/Subbase) } \\
\text { Subgrade }\end{array}$ & $\begin{array}{c}\text { 100 or } 200 \\
\text { Infinite }\end{array}$ & 2800 & 0.4 \\
\hline
\end{tabular}

For layered pavement system, multi-layer elastic theory is applied where the pavement system is considered as horizontally infinite layers. These layers are limited with certain thicknesses in the vertical direction. In pavement analysis it is also usual to consider the last layer (subgrade) as a vertically infinite layer. Therefore, the whole system is modeled as multi-layered semiinfinite half space. The other assumption for elastic solution used in two above mentioned programs is the fully friction condition between two consecutive layers. Finally, the very surface of pavement system is considered as a frictionless layer causing no shear stress (Bodhinayake (2008)).

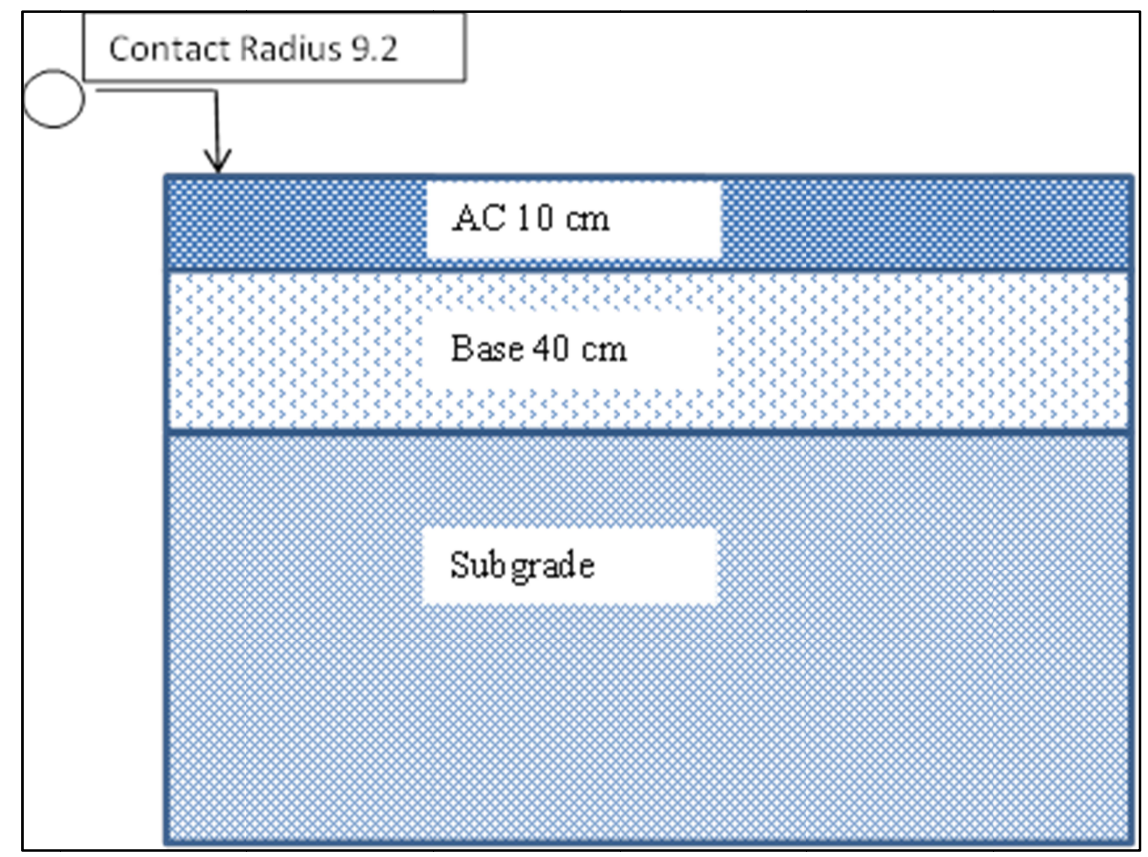

Figure 1. Constructed model in KENLAYER and CIRCLY

Figure 2 illustrates the geometry of FEM axisymmetric model. The geometry of the model in ABAQUS cannot be the same as CIRCLY and KENLAYER as the horizontal and vertical dimensions must be finite in the model. To overcome this problem Duncan et al. (1968) suggested a dimension of 50-times $\mathrm{R}$ (loading radius) in vertical and 12-times $\mathrm{R}$ in horizontal direction. 
Kim and Tutumluer (2009) found a good agreement between results of the FE analysis and KENLAYER when the model dimension is 140-times $\mathrm{R}$ in vertical and 20-times $\mathrm{R}$ in horizontal direction. In this study, the dimension of the model has been selected as 55.55 times $\mathrm{R}$ in horizontal direction and 166.70 times $\mathrm{R}$ in vertical direction. The same ratio has been selected for the plane strain and three dimensional models. Figure 3 shows the geometry of the plane strain and three dimensional models.

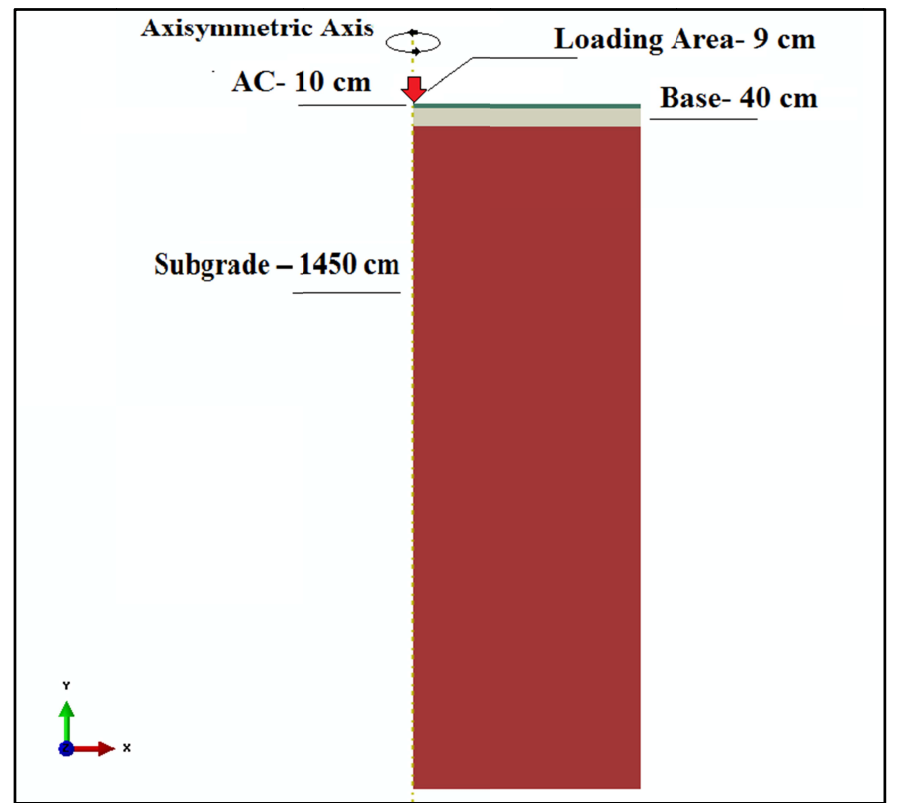

Figure 2. Geometry of the axisymmetric model

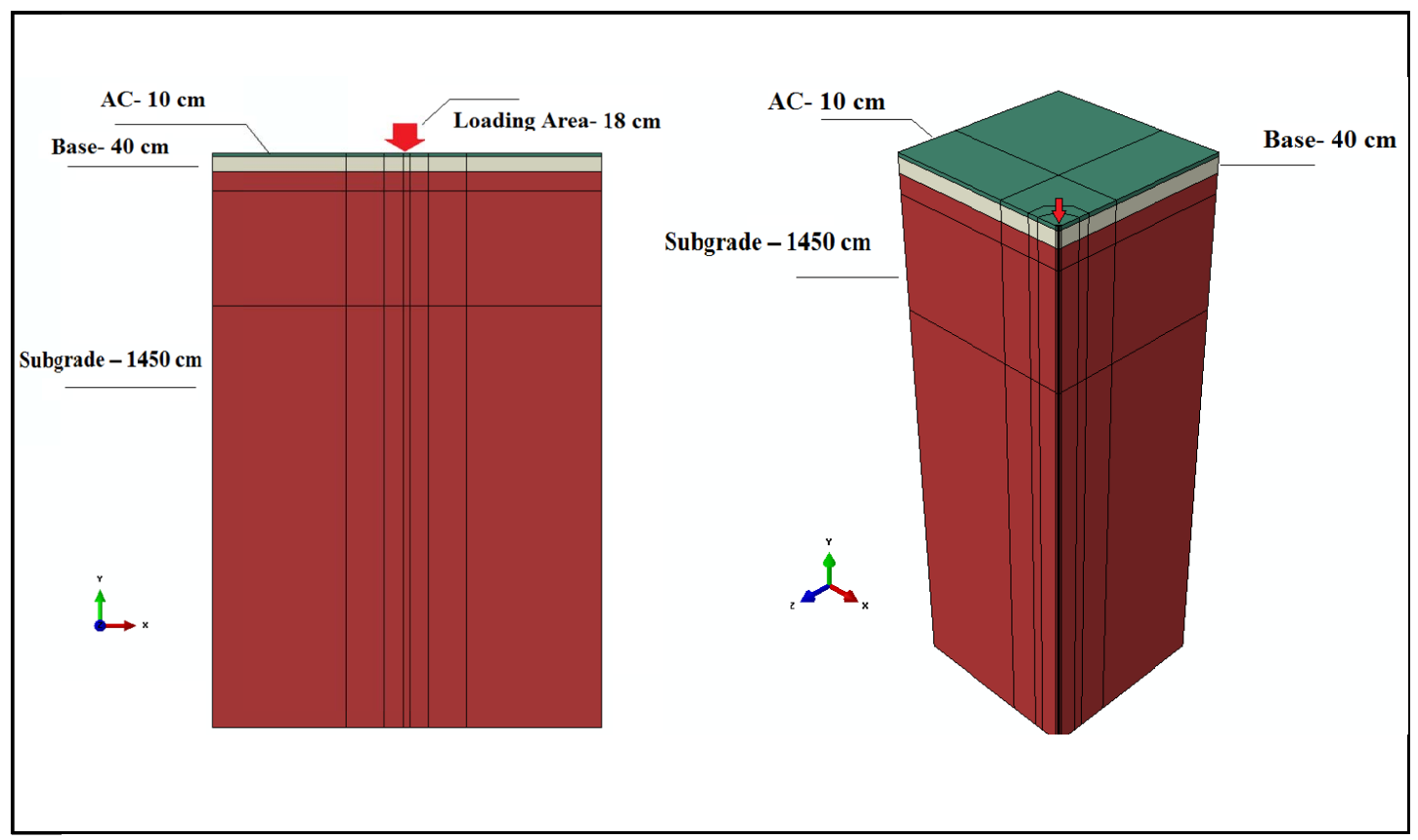

Figure 3. Geometry of the plane strain (left) and 3-D (right) models 


\section{MESH DENSITY AND ELEMEN TYPE}

Figure 4, 5 and 6 illustrate the constructed FE meshes for the axisymmetric, plane strain and the 3-D analysis. Vertical boundaries of the finite element model are modelled using roller boundary conditions which permit the displacement in the vertical direction but prohibit it in the horizontal direction. The lower boundary of the model is fixed in every direction.

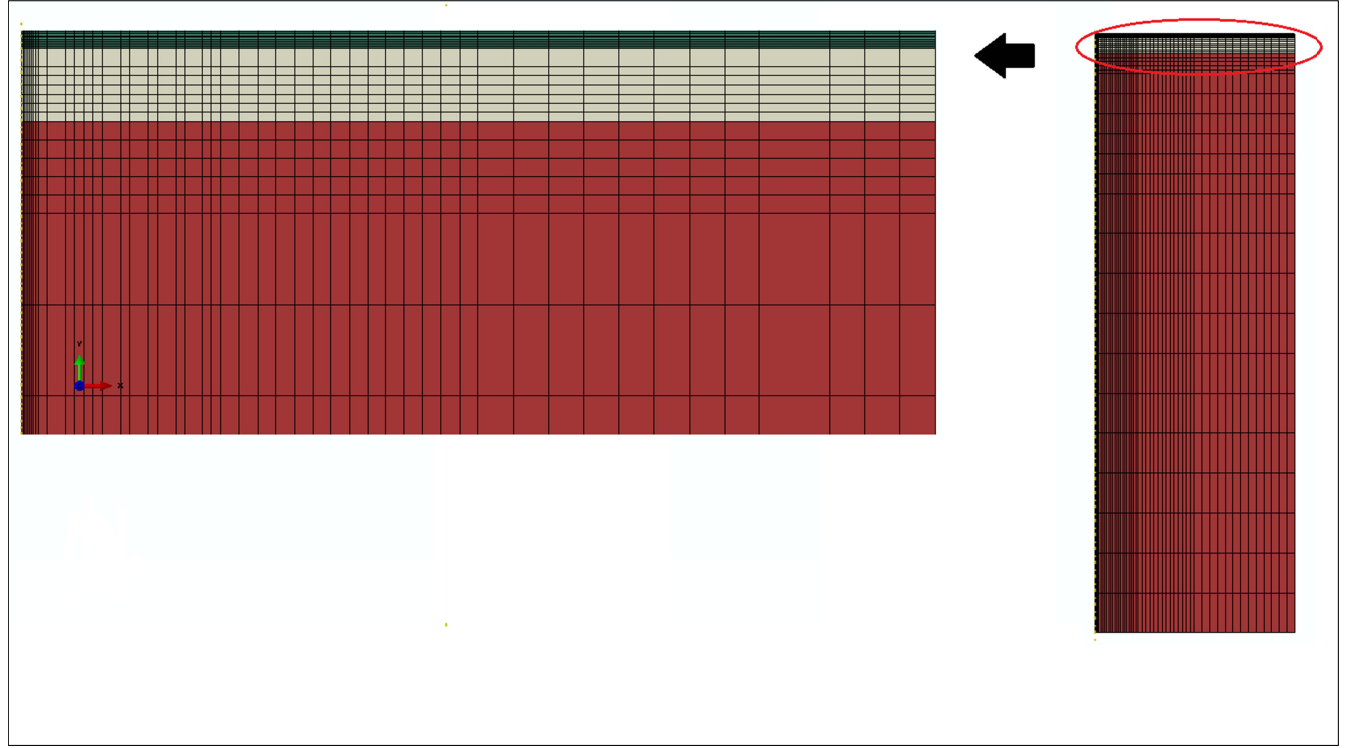

Figure 4 Mesh distributions for the axisymmetric model

For axisymmetric and 3-D model two different types of element and two mesh densifications has been modeled separately.

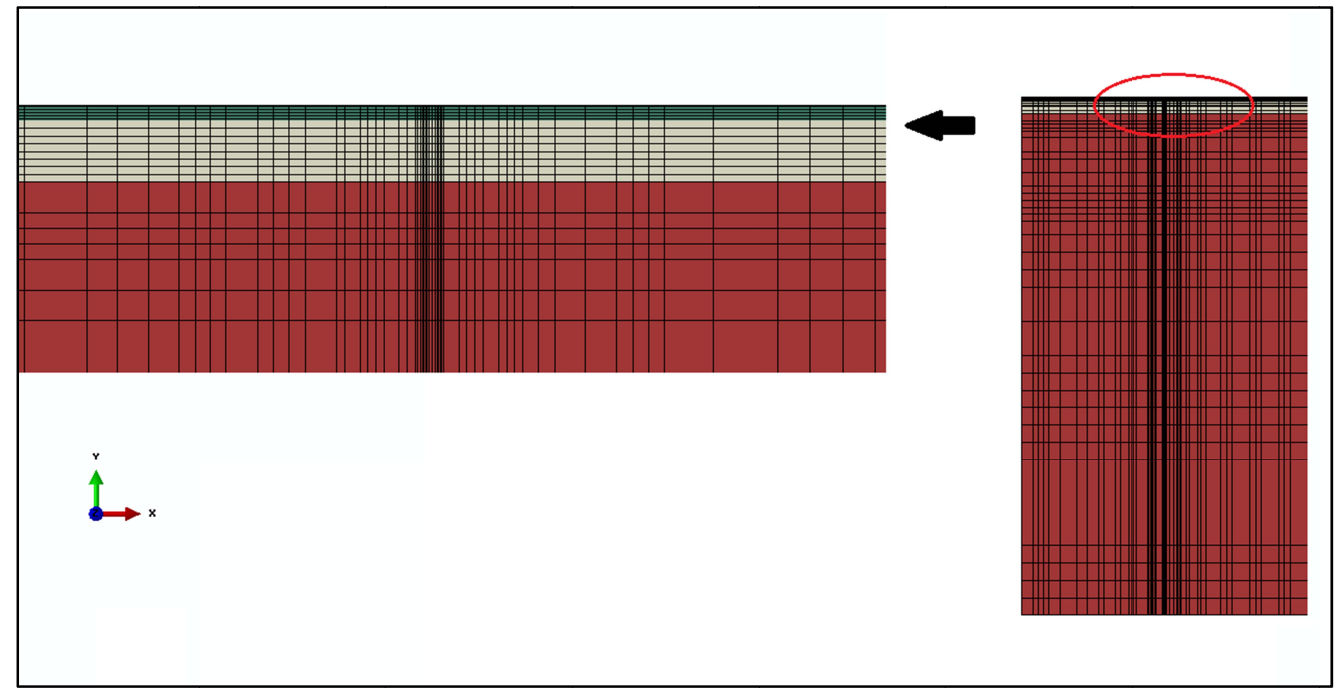

Figure 5. Mesh distribution for the plane strain model

Three axisymmetric models have been investigated: dense axisymmetric 
model has 12656 8-nodes biquadratic axisymmetric quadrilaterall elements; a normal axisymmetric model of 2280 of the same elements; and for the same number of elements (2280) a model has been constructed with 4-node bilinear axisymmetric quadrilateral elements.

Three-dimensional model has also investigated with varying the element types and mesh density. The first model has 86730 of 20 -nodes quadratic brick elements; the second model has the 35000 of the same elements and the third model has 35000 of 8-nodes linear brick elements.

As the results of the analysis illustrated that the plane strain simulation leads to considerably larger values of surface deflection, this model has been excluded from mesh and element investigation.

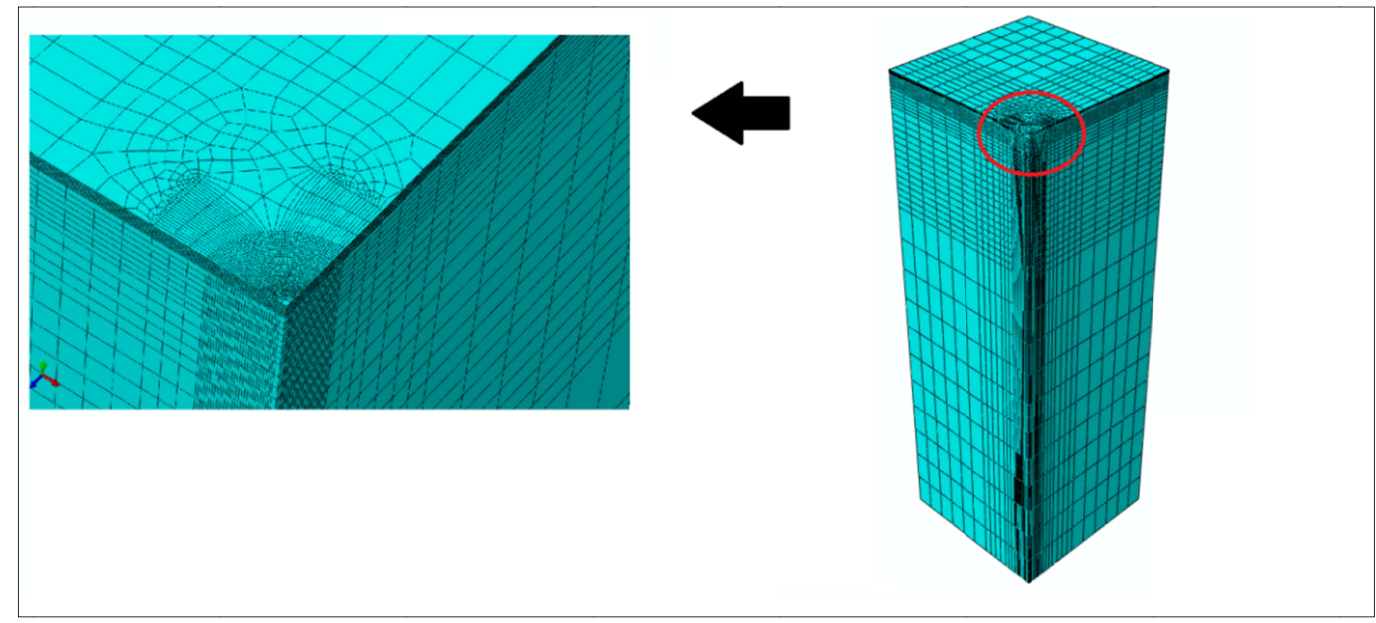

Figure 6. Mesh distribution for the 3-D model

\section{COMPARISON OF THE EFFECTS OF GEOMETRICAL PARAMETERS}

The first step of this analysis is to compare elastic solutions and FEM solutions to determine the range of approximation. In this comparison it has been observed that while there is relative agreement among all constructed models, the plane strain results are out of range and not a reasonable representation of the situation. Figures 7 and 8 show the contours of surface deflection for the three types of the models.

It is clear from these two figure that although the shape of contours in plane strain analysis is acceptable, the value are significantly larger than those calculated from three dimensional model and axisymmetric one.

Figure 9 illustrates the comparison among the models in terms of surface deflection. It can be seen that all the FE models demonstrate the least surface deflection. This is not unusual for it is generally accepted that FEM is slightly stiffer than the actual analytical solution (Helwany 2006). More importantly, there is no meaningful difference among models with dense or normal meshes. This implies mesh independency of the FE models. The 3-D model with 8-noded element has demonstrated a much stiffer response than the others. 


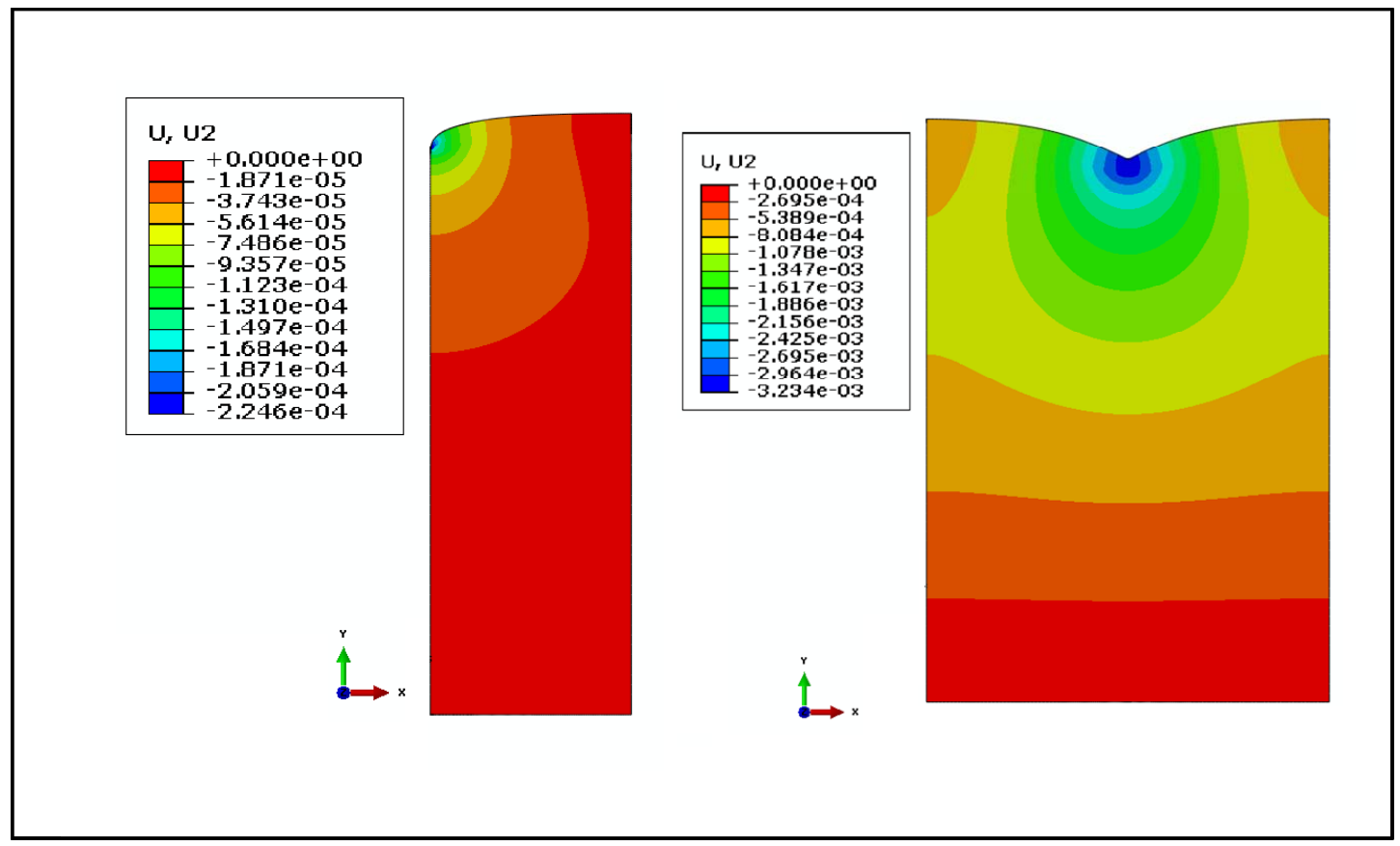

Figure 7. Surface deflection of axisymmetric (left) and plane strain (right) models
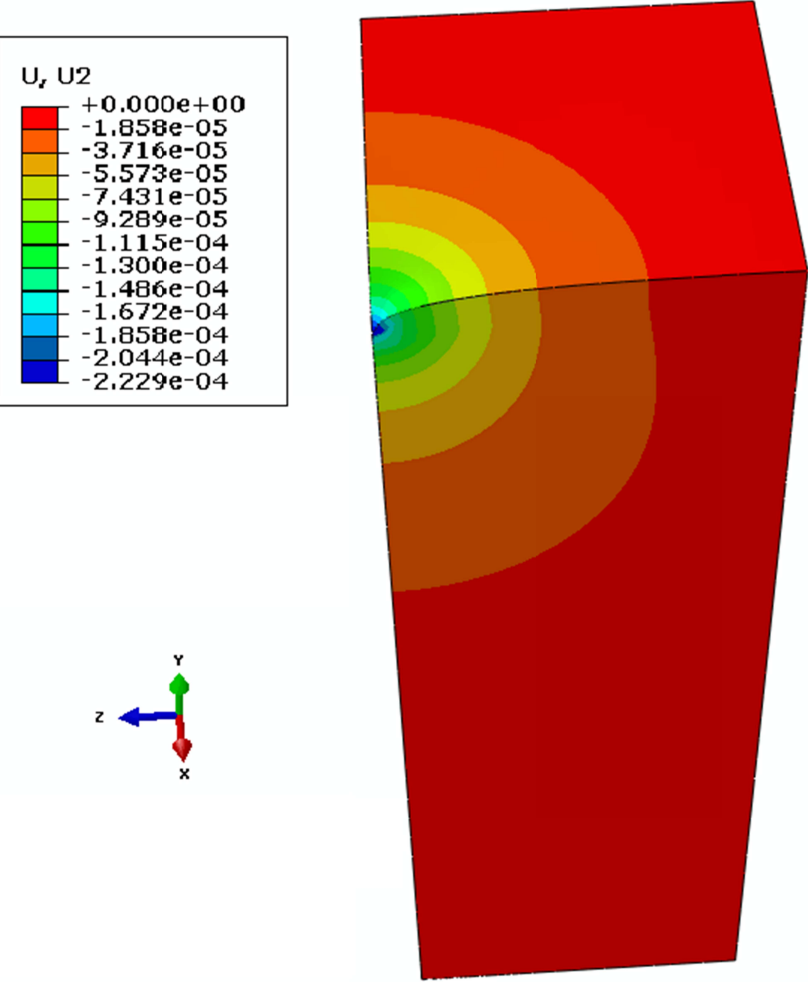
Figure 8. Surface deflection of 3-D model

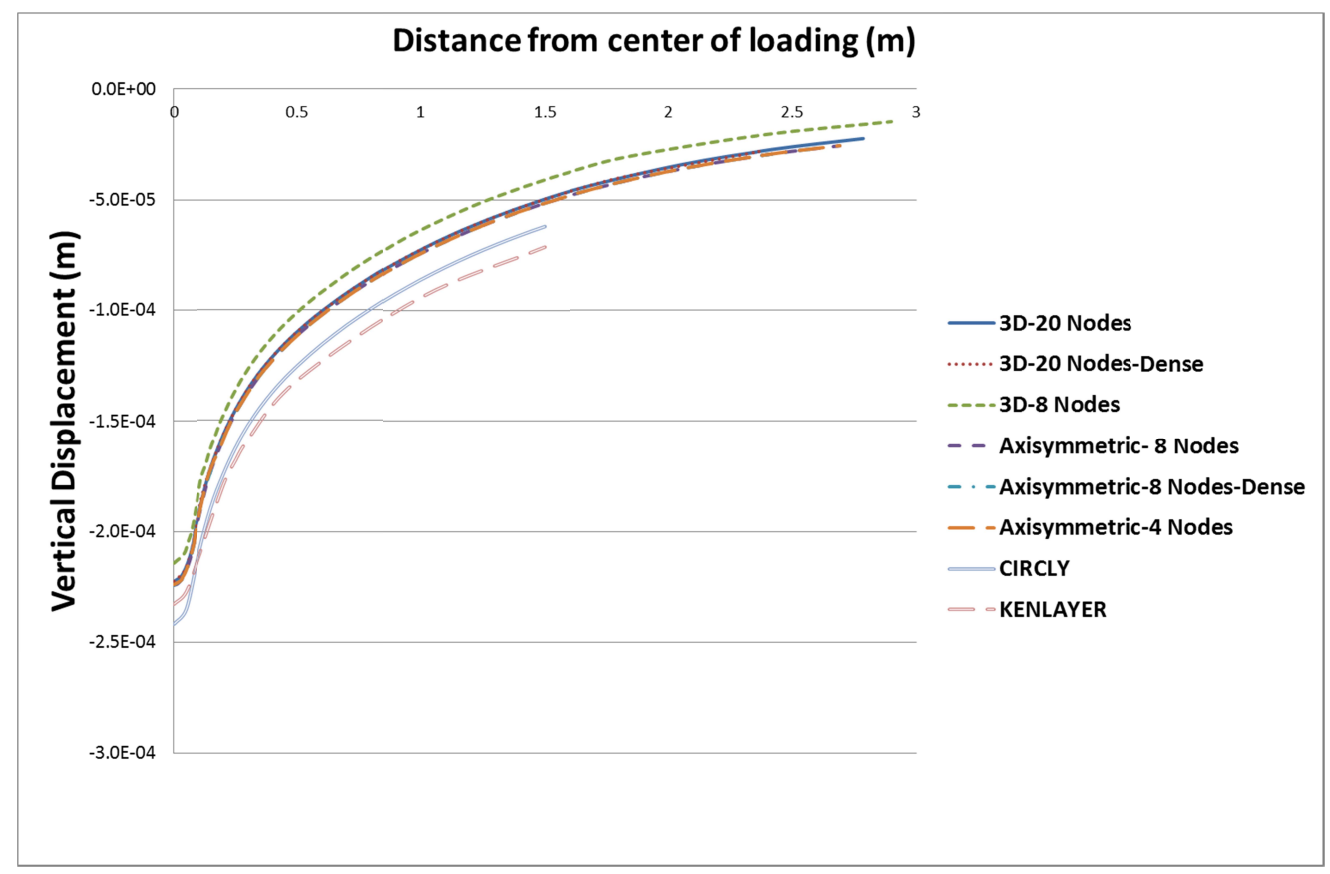

Figure 9. Comparison of the surface deflections for different models

Table 2. Comparison of the results for different models

\begin{tabular}{|c|c|c|c|c|}
\hline Model & $\begin{array}{c}\text { Vertical } \\
\text { Deflection } \\
\text { (Top of } \\
\text { AC) } \\
\end{array}$ & $\begin{array}{c}\text { Horizontal } \\
\text { Strain } \\
\text { (Bottom of } \mathrm{AC} \text { ) }\end{array}$ & $\begin{array}{c}\text { Vertical } \\
\text { Strain } \\
\text { (Top of SG) }\end{array}$ & $\begin{array}{c}\text { Vertical } \\
\text { Stress } \\
\text { (Top of SG) }\end{array}$ \\
\hline CIRCLY & $0.2417 \mathrm{~mm}$ & $-2.44 \mathrm{E}-04$ & $-9.44 \mathrm{E}-05$ & $-11110 \mathrm{~Pa}$ \\
\hline KENLAYER & $0.2327 \mathrm{~mm}$ & $-2.37 \mathrm{E}-04$ & $-9.46 \mathrm{E}-05$ & $-11120 \mathrm{~Pa}$ \\
\hline $\begin{array}{l}\text { ABAQUS } \\
\text { 3D- Dense }\end{array}$ & $0.2224 \mathrm{~mm}$ & $-2.69 \mathrm{E}-04$ & $-8.94 \mathrm{E}-05$ & $-10583 \mathrm{~Pa}$ \\
\hline $\begin{array}{c}\text { ABAQUS } \\
\text { 3D- } 20 \text { Nodes }\end{array}$ & $0.2224 \mathrm{~mm}$ & $-2.60 \mathrm{E}-04$ & $-8.91 \mathrm{E}-05$ & $-10554 \mathrm{~Pa}$ \\
\hline $\begin{array}{c}\text { ABAQUS } \\
\text { 3D- } 8 \text { Nodes }\end{array}$ & $0.2048 \mathrm{~mm}$ & $-2.24 \mathrm{E}-04$ & $-8.37 \mathrm{E}-05$ & $-12299 \mathrm{~Pa}$ \\
\hline $\begin{array}{c}\text { ABAQUS } \\
\text { Axisymmetric- } \\
\text { Dense }\end{array}$ & $0.2240 \mathrm{~mm}$ & $-2.61 \mathrm{E}-04$ & $-9.04 \mathrm{E}-05$ & $-10619 \mathrm{~Pa}$ \\
\hline $\begin{array}{c}\text { ABAQUS } \\
\text { Axisymmetric- } \\
8 \text { Nodes }\end{array}$ & $0.2240 \mathrm{~mm}$ & $-2.61 \mathrm{E}-04$ & $-8.91 \mathrm{E}-05$ & $-10555 \mathrm{~Pa}$ \\
\hline $\begin{array}{c}\text { ABAQUS } \\
\text { Axisymmetric- } \\
4 \text { Nodes }\end{array}$ & $0.2238 \mathrm{~mm}$ & $-2.43 \mathrm{E}-04$ & $-8.48 \mathrm{E}-05$ & $-9332 \mathrm{~Pa}$ \\
\hline Plain strain & $3.2280 \mathrm{~mm}$ & $-2.95 \mathrm{E}-04$ & $-4.94 \mathrm{E}-04$ & $-85024 \mathrm{~Pa}$ \\
\hline
\end{tabular}

There are four critical responses which play a vital role in the flexible 
pavement design. These responses are surface deflection in center of loading, horizontal strain at the bottom of asphalt layer and vertical strain and stress at the top of subgrade layer. The values of these four responses for each of the models have been presented in Table 2. The plane strain model resulted in values considered extreme and beyond possible. For example when the general surface deflection resulted from the other model was between 0.22 to $0.25 \mathrm{~mm}$, the value calculated by plane strain is $3.228 \mathrm{~mm}$ which almost 13 times higher than $0.25 \mathrm{~mm}$. This larger value is attributed to the effect of the loading condition which is a strip of distributed pressure instead of a circular area as is the case in the 3-D, axisymmetric and analytical solution. Therefore it can be said that usage of the plane strain assumption will lead to an overestimation of pavement damage.

The remaining models are in general agreement, however, results of 3-D model with 8-noded elements shows higher discrepancies. The error is especially large for the stress calculation in the subgrade layer (12200.4 pa regarding to 11110 pa calculated from CIRCLY or 11120 pa calculated from KENLAYER). This error (which is almost 10\%) is due to inner approximation of the element (linear interpolation of calculated responses in nodes). Therefore a 4-noded brick cannot be appropriate for this type of pavement modeling.

\section{COMPARISON OF THE EFFECTS OF LAYER THICKNESS}

The second part of the analysis is to investigate the effect of variation in layer thicknesses and the influence it has between different models.

Table 3. Effect of layer thickness on the numerical approximation

\begin{tabular}{|c|c|c|c|c|}
\hline Model & $\begin{array}{l}\text { Vertical } \\
\text { Deflection } \\
\text { (Top of } \\
\text { AC) }\end{array}$ & $\begin{array}{c}\text { Horizontal } \\
\text { Strain } \\
\text { (Bottom of } \mathrm{AC} \text { ) }\end{array}$ & $\begin{array}{l}\text { Vertical } \\
\text { Strain } \\
\text { (Top of } \\
\text { SG) }\end{array}$ & $\begin{array}{c}\text { Vertical } \\
\text { Stress } \\
\text { (Top of SG) }\end{array}$ \\
\hline $\begin{array}{c}\text { CIRCLY } \\
(10-\mathrm{cm} \mathrm{AC)}\end{array}$ & $0.2327 \mathrm{~mm}$ & $-2.37 \mathrm{E}-04$ & $-9.46 \mathrm{E}-05$ & $-11120 \mathrm{~Pa}$ \\
\hline $\begin{array}{r}\text { KENLAYER } \\
(10-\mathrm{cm} \text { AC) }\end{array}$ & $0.2224 \mathrm{~mm}$ & $-2.69 \mathrm{E}-04$ & $-8.94 \mathrm{E}-05$ & $-10583 \mathrm{~Pa}$ \\
\hline $\begin{array}{c}\text { ABAQUS } \\
(10-c m \text { AC) }\end{array}$ & $0.2240 \mathrm{~mm}$ & $-2.61 \mathrm{E}-04$ & $-8.91 \mathrm{E}-05$ & $-10555 \mathrm{~Pa}$ \\
\hline $\begin{array}{c}\text { CIRCLY } \\
(20-\mathrm{cm} \mathrm{AC)}\end{array}$ & $0.1737 \mathrm{~mm}$ & $-9.45 \mathrm{E}-05$ & $-5.46 \mathrm{E}-05$ & $-6462 \mathrm{~Pa}$ \\
\hline $\begin{array}{c}\text { KENLAYER } \\
\text { (20-cm AC) }\end{array}$ & $0.1595 \mathrm{~mm}$ & $-1.01 \mathrm{E}-04$ & $-5.47 \mathrm{E}-05$ & $-6451 \mathrm{~Pa}$ \\
\hline $\begin{array}{c}\text { ABAQUS } \\
(20-\mathrm{cm} \text { AC) }\end{array}$ & $0.1653 \mathrm{~mm}$ & $-1.10 \mathrm{E}-04$ & $-5.40 \mathrm{E}-05$ & $-6426 \mathrm{~Pa}$ \\
\hline $\begin{array}{c}\text { CIRCLY } \\
\text { (60-cm Base) }\end{array}$ & $0.2144 \mathrm{~mm}$ & $-2.37 \mathrm{E}-04$ & $-6.56 \mathrm{E}-05$ & $-7696 \mathrm{~Pa}$ \\
\hline $\begin{array}{l}\text { KENLAYER } \\
\text { (60-cm Base) }\end{array}$ & $0.2053 \mathrm{~mm}$ & $-2.31 \mathrm{E}-04$ & $-6.57 \mathrm{E}-05$ & $-7686 \mathrm{~Pa}$ \\
\hline ABAQUS & $0.2059 \mathrm{~mm}$ & $-2.60 \mathrm{E}-04$ & $-6.48 \mathrm{E}-05$ & $-7645 \mathrm{~Pa}$ \\
\hline
\end{tabular}




\section{(60-cm Base)}

Here, three different pavement structures have been studied. The first structure is the same as figure 1 with a $10 \mathrm{~cm}$ asphalt layer and a $40 \mathrm{~cm}$ base layer. The second structure is a $20 \mathrm{~cm}$ asphalt layer and a $40 \mathrm{~cm}$ of base layer. The third has a $10 \mathrm{~cm}$ asphalt layer and a $60 \mathrm{~cm}$ base layer. Finite element modeling is in axisymmetric 8-noded element with normal mesh density.

Table 3 represents the results of four critical responses for three different pavement structures. There is an acceptable agreement among the results, however, the calculated horizontal strain at the bottom of asphalt layer from the ABAQUS has a higher value than KENLAYER and CIRCLY but the difference is less than $10 \%$.

It can be seen that the thickness of the layer does not significantly influence the outcomes and there is general agreements among the numerical models.

\section{CONCLUSION}

An in-depth investigation of the effects of geometrical parameters and their influence on the results of numerical modeling has been undertaken. FE modeling has analysed in 2-D plane strain, 2-D axisymmetric, 3-D and analytical elastic solution. The influence of mesh density and elements' type has been compared and finally a separate analysis has been done to consider the effect of modification of layers thickness over the consistency of the results of the numerical models.

According to the analyses the following outcome can be concluded:

1) The plane strain model results in extremely severe response by the pavement system in comparison to the results of the analytical solution, axisymmetric solution and 3-D model. Therefore, using of this simplification should be with extreme caution.

2) The 8-nodes brick elements lead to a stiffer medium and the results of the analysis has a range of $10 \%$ approximation.

3) The 8-noded axisymmetric elements or 20-noded brick element provide close approximation to the currently used linear elastic solutions.

It is worth to mention that all analyses in this study is carried out in the linear elastic assumption which is not true representation of the flexible layered pavement behavior. A non-linear elastoplastic analysis is required for further study.

\section{REFERENCE}

AUSTROADS (2004). Pavement Design - A Guide to the Structural Design of Road Pavements, Austroads, Sydney, Australia.

Bodhinayake, B. C. (2008). "A study on nonlinear behaviour of subgrades under cyclic loading for the development of a design chart for flexible pavements." University of Wollongong Thesis Collection: 868.

Cho, Y. H., B. F. McCullough, et al. (1996). "Considerations on finite- 
element method application in pavement structural analysis." Transportation Research Record: Journal of the Transportation Research Board 1539(-1): 96101.

Duncan, J. M., C. L. Monismith, et al. (1968). "Finite element analyses of pavements." Highway Research Record Highway Research Board, Washington D. C. 228: 18-33.

Gedafa, D. S. (2006). "Comparison of Flexible Pavement Performance Using Kenlayer and HDM-4." Midwest Transportation Consortium, Ames, Iowa.

Hadi, M. and M. Symons (1996). "Computing stresses in road pavements using CIRCLY, MSC/NASTRAN and STRAND6." Transactions of the Institution of Engineers, Australia. Civil engineering 38(2-4): 89-93.

Helwany, S. (2006). Applied soil mechanics, Wiley Online Library.

Hibbit, K., and Sorenson, Inc. (2010). ABAQUS User's Manual. Providence, RI.

Holanda, Á. S., E. Parente Junior, et al. (2006). Finite element modeling of flexible pavements, Iberian Latin American Congress on Computational Methods in Engineering.

Huang, Y. (1969). Finite element analysis of nonlinear soil media. Proceedings, Symposium on Application of Finite Element Methods in Civil Engineering, , Vanderbilt University, Nashville, The Netherlands.

Huang, Y. H. (1993). Pavement analysis and design, Prentice-Hall Inc., New Jersey, USA.

Huang, Y. H. (2004). Pavement analysis and design, Pearson Prentice Hall, Pearson Education Inc., USA.

Kim, M. (2007). Three-dimensional finite element analysis of flexible pavements considering nonlinear pavement foundation behavior, University of Illinois.

Kim, M. and E. Tutumluer (2006). Modeling Nonlinear, Stress Dependent Pavement Foundation Behavior Using a General Purpose Finite Element Program, ASCE.

Kim, M., E. Tutumluer, et al. (2009). "Nonlinear pavement foundation modeling for three-dimensional finite-element analysis of flexible pavements." International Journal of Geomechanics 9: 195.

Mallela, J. and K. George (1994). "Three-dimensional dynamic response model for rigid pavements." Transportation Research Record(1448).

Myers, L. A., R. Roque, et al. (2001). "Use of Two-dimensional Finite Element Analysis to Represent Bending Response of Asphalt Pavement Structures." International Journal of Pavement Engineering 2(3): 201-214.

Tutumluer, E., D. N. Little, et al. (2003). "Validated model for predicting field performance of aggregate base courses." Transportation Research Record: Journal of the Transportation Research Board 1837(-1): 41-49.

Uddin, W., D. Zhang, et al. (1994). "Finite element simulation of pavement discontinuities and dynamic load response." Transportation Research Record(1448).

Wardle, L. (1977). Program CIRCLY: A Computer Program for the Analysis of Multiple Complex Circular Loads on Layered Anisotropic Media. 
User's Manual, Division of Applied Geomechanics, Commonwealth Scientific and Industrial Research Organization Australia.

Yu, H. S. (2006). Plasticity and geotechnics, Springer.

Zaghloul, S. and T. White (1993). "Use of a three-dimensional, dynamic finite element program for analysis of flexible pavement." Transportation Research Record(1388): 60-69. 